\title{
Dynamics of bacterial community exposed to hydrocarbons and oleophilic fertilizer in high-Arctic intertidal beach
}

\author{
Stian Røberg • Jan Ivar Østerhus • Bjarne Landfald
}

Received: 3 December 2010 / Revised: 21 March 2011 / Accepted: 22 March 2011 / Published online: 6 April 2011

(C) The Author(s) 2011. This article is published with open access at Springerlink.com

\begin{abstract}
Exposure of pristine microbial environments to hydrocarbon contamination stimulates growth of the initially small fraction of indigenous hydrocarbon-degrading bacteria. Custom-made oleophilic fertilizers have been demonstrated to promote oil bioremediation by boosting this proliferation. In the present study, the temporal dynamics of the bacterial community structure and the individual influences of hydrocarbons and an oleophilic fertilizer in shaping the community structure was explored during a 78 days bioremediation experiment in a high-Arctic intertidal beach environment. A combination of cultivation-independent 16S rRNA gene length-heterogeneity polymerase chain reaction (LH-PCR) profiling and identification of hydrocarbon-degrading isolates based on partial 16S rRNA gene sequences was employed. LH-PCR community profiles in the fertilizer alone and fertilized kerosene plots were largely indistinguishable throughout the experimental period, while kerosene alone plots showed a markedly different composition of dominant groups. This pointed to the fertilizer as the more decisive factor in shaping the community structure. Most prominent LH-PCR fragments which emerged after kerosene or fertilizer addition could be provisionally assigned to bacterial taxa through coinciding LH-PCR fragment lengths with hydrocarbon-degrading isolates obtained from the same type of experimental units. However, a few quantitatively significant LH-PCR groups
\end{abstract}

Electronic supplementary material The online version of this article (doi:10.1007/s00300-011-1003-4) contains supplementary material, which is available to authorized users.

S. Røberg · J. I. Østerhus · B. Landfald ( $₫)$

Norwegian College of Fishery Science,

University of Troms $\varnothing, 9037$ Troms $\varnothing$, Norway

e-mail: bjarne.landfald@uit.no had no counterparts among the cultivated bacteria. One of these was affiliated to a hitherto unspeciated subgroup within the Alkanindiges/Acinetobacter clade of Moraxellaceae by a $16 \mathrm{~S}$ rRNA gene cloning approach.

Keywords Bioremediation $\cdot$ Hydrocarbons $\cdot$ Svalbard . Intertidal $\cdot$ LH-PCR

\section{Introduction}

Accidental hydrocarbon releases are particularly challenging in permanently cold regions, where abiotic removal tends to be slow. Evaporation of the oil is reduced, while viscosity is increased, as compared with warmer climates (Jarsjö et al. 1997; Fingas 2004). Furthermore, inclusion of oil in permanent or seasonal ice poses specific problems in the polar marine environments. The extent of the microbial response may therefore be particularly decisive for the permanence of spills in the cold regions of the World.

Hydrocarbon-degrading bacteria are ubiquitous in pristine terrestrial and marine environments due to releases from biogenic sources and, at some places, seepage from geological reservoirs. However, the hydrocarbon consumers normally constitute a minor fraction of the overall bacterial community. After accidental releases or at permanently oil-exposed locations, their numbers typically increase by orders of magnitude, making hydrocarbondegrading bacteria a major fraction of the community. Biodegradation may contribute significantly to the removal of hydrocarbon contaminants in such environments (Margesin and Schinner 1999; Delille et al. 2009).

A broad range of bacterial phylogenetic groups, comprising at least 79 species, has been identified as hydrocarbon-degrading bacteria (reviewed by Prince 2005). The 
majority belongs to the Proteobacteria, but representatives of the Firmicutes, Actinobacteria, and Bacteroidetes phyla are also frequently encountered. The actual bacterial community structure in hydrocarbon-contaminated locations is influenced both by the inherent characteristics of the environment, the nature of the spill (i.e. chemical composition, acute or chronic) and the kind of bioremediation measures adopted. Furthermore, temporal changes must be expected to result from chemical and physical conversions, removal of the spill or seasonal variations. As a rule, the growth stimulation brought about by hydrocarbons has been shown to lead to reduced community diversity. This effect seems enhanced by nutrient addition (Macnaughton et al. 1999; Röling et al. 2002).

Commonly, hydrocarbon biodegradation in aerobic environments is restricted by the availability of the macronutrients nitrogen and phosphorus. Thus, the most efficient bioremediation measure has repeatedly been demonstrated to be the addition of these nutrients, either as slow-release inorganic fertilizers or as components of specially developed oleophilic bioremediation agents (Swannell et al. 1996; Zhu et al. 2004). Although results are conflicting, most studies conclude that fertilization stimulates proliferation of hydrocarbon-degrading bacteria and thereby biodegradation rates (Atlas 1995; Mearns 1997; Delille et al. 1998; Jiménez et al. 2007; Margesin et al. 2007; Delille 2009; Vázquez et al. 2009). However, the effects on beached spills are often short term, as the nutrients tend to be washed out of the system more rapidly than the hydrocarbons themselves (Xu and Obbard 2003).

In a bioremediation study which involved addition of kerosene to a high-Arctic intertidal beach sediment (Røberg et al. 2007), we observed an oleophilic fertilizer $\left(\right.$ Inipol $^{+}$, a cold climate adapted variant of the well-known Inipol EAP22) to have a strong impact on the size and temporal fluctuation in the population of viable hydrocarbon-degrading bacteria. Paradoxically, the impact was equally strong if the fertilizer-containing no hydrocarbon ingredients - was added alone, i.e. not as a nutrient amendment to the hydrocarbon contamination. A similar effect is reported with Inipol EAP22 in an Antarctic soil mesocosm experiment (Delille and Coulon 2008). Our study indicated the fertilizer to be the more influential component in shaping the hydrocarbon-degrading bacterial community in this kind of bioremediation system. The present study addresses this question by exploring the separate effects on bacterial community development of adding the kerosene contaminant and oleophilic fertilizer. We furthermore elucidate to what extent prominent hydrocarbon-degrading bacteria, as obtained by cultivation, correspond to prominent community operational taxonomic units as revealed by cultivation-independent $16 \mathrm{~S}$ rRNA gene-based profiling.

\section{Experimental procedures}

\section{Field experiment}

An experiment involving the addition of a kerosene-based hydrocarbon mixture and oleophilic fertilizer to tube enclosures in the intertidal zone was carried out in 2003 at the desolate location Kapp Wijk, Svalbard $\left(78^{\circ} 36.5^{\prime} \mathrm{N}\right.$, $\left.15^{\circ} 10^{\prime} \mathrm{E}\right)$. The hydrocarbons were composed of a low-aromatics $(<0.3 \%) \quad 190-250^{\circ} \mathrm{C}$ boiling point kerosene product (Fluka) supplemented with heavier, individual alkanes in the size range $\mathrm{C}_{16}-\mathrm{C}_{20}$ (all Fluka). These additions varied from 1.3 to $4.0 \%$ by weight of the kerosene. The experimental cold climate adapted Inipol ${ }^{+}$(CECA SA, France) was employed as fertilizer. According to the manufacturer, it contained $22.4 \%$ of a phosphate-containing surfactant (not specified), $16 \%$ of a co-surfactant (not specified), $14.4 \%$ urea, $25 \%$ oleic acid and $22.3 \%$ water (F. Périé, personal communication). Kerosene and fertilizer were added in amounts equivalent to 7 and $0.71 \mathrm{~m}^{-2}$, respectively. The same amount of the fertilizer was applied again 43 days after the start of the experiment.

Twelve PVC tubes $(30 \mathrm{~cm}$ inner diameter $\times 100 \mathrm{~cm}$, separated by $2 \mathrm{~m}$ ) were dug into the intertidal beach sediment in a lagoon well protected from wave action. The experimental field showed no traceable variation regarding topology, grain size distribution, wave exposure or influx of nutrients. The sediment was an even mixture of sand and gravel, with $94 \%$ of dry weight, on average, in the 0.25 $8 \mathrm{~mm}$ grain size range (Røberg et al. 2007). Seawater percolated easily through this substrate and the tidal oscillations inside the enclosures were in close synchrony with the surrounding water. The water level at high tide never overflowed the upper edge of the tubes (Røberg et al. 2007). The surface sediment temperature inside the enclosures fluctuated in the range $6-11^{\circ} \mathrm{C}$ throughout the first 7 weeks of the experiment. Thereafter, temperature dropped toward freezing conditions by the time of the last sampling in late September.

Triplicate enclosures were subjected to the following four treatments: (a) no additions (control), (b) kerosene added alone, (c) fertilizer added alone, and (d) kerosene + fertilizer added. Duplicate sediment samples were collected in $50 \mathrm{ml}$ sterile plastic tubes from the upper $5 \mathrm{~cm}$ surface layer and immediately cooled in wet ice to $0^{\circ} \mathrm{C}$ to minimize changes in bacterial community structure during transport to the laboratory within $4 \mathrm{~h}$. Immediately on arrival, sample suspensions were obtained by vigorously shaking $25 \mathrm{~g} \mathrm{sam}$ ples in $25 \mathrm{ml}$ phosphate-buffered $2 \% \mathrm{NaCl}$ (PBS) for $1 \mathrm{~min}$, followed by sedimentation for $10 \mathrm{~min}$. Samples of the resulting fine particulate supernatants were immediately used for viable bacteria cultivation or frozen at $-20^{\circ} \mathrm{C}$ for subsequent DNA extraction. Hence, identically processed 
samples were used for obtaining representative isolates and for cultivation-independent studies. Samples from experimental units added kerosene or fertilizer were collected 2 , $8,18,43,49$, and 78 days after start on 7 July 2003. For practical reasons, control units (no additions) were sampled after 0,18 , and 78 days only. Further details on field site, sediment characteristics, experimental setup, and sampling procedures are presented elsewhere (Røberg et al. 2007).

\section{LH-PCR}

Environmental DNA was extracted from $2 \mathrm{ml}$ of thawed sediment suspensions (see above) by employing the Mobio Power Soil kit (MOBIO Laboratories Inc.) according to the manufacturer's instructions. The DNA extracts were PCR amplified with the carboxyfluorescein (6-FAM)-labeled forward primer 27F (AGAGTTTGATCMTGGCTCAG) and the reverse primer 338R (GCTGCCTCCCGTAGGA GT), covering two variable regions of the 16S rRNA gene (Suzuki et al. 1998). Amplification was conducted in $50 \mu \mathrm{l}$ buffered (DyNAzyme, Finnzymes) reaction volumes containing $2.5 \mathrm{mM} \mathrm{MgCl}_{2}$ in total, $0.1 \mathrm{mM}$ each of dNTPs, $50 \mathrm{ng}$ each of primers, $0.4 \mathrm{U}$ DyNAzyme II DNA polymerase (Finnzymes), $2 \mu \mathrm{l}$ DNA extract. An initial 10 min denaturation at $94^{\circ} \mathrm{C}$ was followed by 20 cycles of $94^{\circ} \mathrm{C}$ for $20 \mathrm{~s}, 55^{\circ} \mathrm{C}$ for $30 \mathrm{~s}, 72^{\circ} \mathrm{C}$ for $60 \mathrm{~s}$. A final extension was conducted at $72^{\circ} \mathrm{C}$ for $10 \mathrm{~min}$. Products were precipitated in ethanol, redissolved in $20 \mu \mathrm{l}$ formamide solution (Applied Biosystems) and added $8 \mu \mathrm{l}$ of the 1/100 diluted internal size standard GeneScan 500LIZ (Applied Biosystems). After $5 \mathrm{~min}$ denaturation at $95^{\circ} \mathrm{C}$ followed by $7 \mathrm{~min}$ at $4^{\circ} \mathrm{C}$, the products were applied on the capillary sequencer ABI 3100 (Applied Biosystems) with POP6 polymer. The GeneMapper ${ }^{\circledR}$ v3.5 (Applied Biosystems) software, with the Southern size calling algorithm and 20 relative fluorescent units as noise threshold value, was used to determine fragment lengths and peak heights/areas. A minimum of triplicate LH-PCR were run on each DNA extract. Sporadically some peak displacement (generally in the range $0.1-0.3 \mathrm{bp}$ ) was observed between replicate runs analyzed at separate dates, but reproducible fragment patterns made consistent alignment of identical peaks feasible. Detected fragments from all samples were size categorized at a $0.1 \mathrm{bp}$ division level in a spreadsheet. Evident groupings of fragments comprising size ranges of \pm 0.3 bp or less were binned into length heterogeneity fragments (LHFs) assigned the median within-group fragment size. Only peaks which exceeded the $1 \%$ threshold level (see below) in at least two-thirds of replicates were included as an LHF of a given sample. The operational taxonomic unit (OTU) richness in individual samples was estimated as the number of LHFs and the corresponding diversities as the Shannon index, $H^{\prime}=-\Sigma p_{\mathrm{i}} \ln p_{\mathrm{i}}$, where $p_{\mathrm{i}}$ represents the relative contribution by $\mathrm{LHF}_{\mathrm{i}}$ to overall peak area (Shannon and Weaver 1963) and the Simpson index (Simpson 1949) in the modified form $D=1-\Sigma\left[\left(n_{\mathrm{i}}\left(n_{\mathrm{i}}-1\right) / N(N-1)\right]\right.$ where $n_{\mathrm{i}}$ is the percentage of $\mathrm{LHF}_{\mathrm{i}}$ and $N=100$.

DNA extracts from the hydrocarbon degrading bacterial isolates, as well as plasmid preparations of cloned $16 \mathrm{~S}$ rRNA genes (see below) were subjected to amplification and fragment length estimation by the described LH-PCR procedure to examine the level of coincidence between prominent LHFs and isolates/clones.

Isolation of hydrocarbon-degrading bacteria

Collections of bacterial isolates which utilized the kerosene as sole carbon and energy source were obtained from samples collected on day 49 of the experiment. Appropriate dilutions of fresh sediment suspensions (see above) were plated on Petri dishes with Bushnell-Haas medium (Difco) supplemented with $2 \% \mathrm{NaCl}$ and solidified by $1.5 \%$ agar. The plates were incubated at $6^{\circ} \mathrm{C}$ for 5-9 weeks in a saturated kerosene atmosphere (Dandie et al. 2001), which was maintained at all time during incubation. Representative isolates were picked from the primary plates and re-streaked twice by the same cultivation procedure. Purified isolates with marked growth (i.e. too strong to be explained by contaminating metabolites in the agar) were kept as hydrocarbon-degrading bacteria. As all hydrocarbon-degrading isolates also showed rapid growth on non-selective medium, they were cultivated in liquid marine broth/peptone medium (Røberg et al. 2007) for cryopreservation and DNA extraction.

16S ribosomal RNA gene amplification and sequencing of isolates

Liquid cultures of bacterial isolates were incubated on a rotary shaker at $6^{\circ} \mathrm{C}$ until visible turbidity. DNA was extracted from $1 \mathrm{ml}$ of the cultures according to Pitcher et al. (1989) or Ausubel et al. (1994). The conserved bacterial primers 27F (see above) and 1492R (GGTTACCT TGTTACGACTT) (Suzuki et al. 1998) were used for PCR amplification of the major part of the 16S rRNA gene of the isolates. The 50- $\mu 1$ reaction volumes contained DyNAzyme polymerase buffer (Finnzymes), $0.2 \mathrm{mM}$ each of dNTPs, $50 \mathrm{ng}$ each of the primers, 0.4 U DyNAzyme II DNA polymerase (Finnzymes), $2 \mu \mathrm{l}$ DNA extract. An initial $10 \mathrm{~min}$ of denaturation at $94^{\circ} \mathrm{C}$ was followed by 30 cycles of $94^{\circ} \mathrm{C}$ for $30 \mathrm{~s}, 53^{\circ} \mathrm{C}$ for $45 \mathrm{~s}$, and $72^{\circ} \mathrm{C}$ for $90 \mathrm{~s}$. A final extension was conducted at $72^{\circ} \mathrm{C}$ for $7 \mathrm{~min}$. PCR products were purified by the Qiaquick PCR purification kit (Qiagen) according to the manufacturer's instructions and dissolved in sterile ultra pure water. The amplified 16S rRNA genes were sequenced by use of the primers $27 \mathrm{~F}$ (see above) 
and/or 518R (5'-ATTACCGCGGCTGCTGG-3') (Muyzer et al. 1993). Sequences in the range 353-588 bp were checked for anomalies with the Web-based software tools Mallard and Pintail (Ashelford et al. 2005) and deposited in the EMBL Nucleotide Sequence Database under the accession numbers AM931080 to AM931149.

\section{Clone libraries}

Minor clone libraries were constructed from two samples where prominent LH-PCR peaks were not represented by isolates with the same LH-PCR fragment length. Extracted environmental DNA was PCR amplified by the $27 \mathrm{~F}$ and $1492 \mathrm{R}$ primers as described, purified and cloned into the pGEM T Easy vector (Promega) according to the manufacturer's instructions. Plasmids from 15 randomly picked transformants from each sample were purified with E.N.Z.A. plasmid miniprep kit (Omega Bio-Tek) and subjected to LH-PCR fragment size estimation, as described. Clones with relevant fragment sizes were end sequenced from the vector-coded primer binding sites SP6 and T7. A sequence covering the complete $27 \mathrm{~F} / 1492 \mathrm{R}$ amplicon was obtained by additionally employing the internal sequencing primers 518R (see above) and 517F (GCCAGCAGCCGCGGTAA) on a single plasmid preparation.

Sequence-based identification

Tentative identities of isolates and clones from their partial 16S rRNA gene sequences were obtained by querying the Ribosomal Database Project (Cole et al. 2007). Hierarchical taxonomic assignments were made by the naïve Bayesian rRNA gene Classifier program (Wang et al. 2007) and similar sequences were grouped within their lowest common taxonomic rank (genus or family) based on a $97 \%$ bootstrap confidence level. The phylogenetic relationship of the cloned $\mathrm{LHF}_{340}$ partial $16 \mathrm{~S}$ rRNA gene was inferred from a 1,458-bp sequence (EMBL accession number AM905315) by the neighbor-joining algorithm, as implemented in the ClustalX alignment/tree generation software (Thompson et al. 1997).

\section{Statistical methods}

The length categorized GeneMapper ${ }^{\circledR}$ fragment data of each sample were normalized as percentage LHF distribution-after excluding fragments constituting less than $1.0 \%$ by area of the most prominent peak. Fragment patterns were compared by means of the multivariate principal component analysis (PCA) tool (Wold et al. 1987), as implemented in the software package The Unscrambler (Camo AS, Norway), after log transformation into the correspond- ing $\log (\%$ of total area +1$)$ values. The statistical significance of treatment and temporal differences in numbers of LHFs was tested by two-way ANOVA (Microsoft Excel Data Analysis Tool).

\section{Results}

\section{LH-PCR fragment richness}

Cultivation-independent identification of operational taxonomic units (OTUs) was based on length-heterogeneity polymerase chain reaction (LH-PCR) (Suzuki et al. 1998). The applied fragment separation technology showed confident sub-basepair resolution, and with a tolerance of \pm 0.3 bp units, 40 differently sized 27F/338R LH-PCR fragments (LHFs) were distinguishable in the altogether 63 samples which were analyzed. Most median LHF length estimates deviated by $0.1-0.5 \mathrm{bp}$ units from the intrinsic integer lengths of DNA fragments. As the deviations were both on the positive and negative side of closest integer length, common rules for rounding off resulted in two discernable LHFs of the same integer length (marked $a$ and $b$, respectively) in five cases. The fragment size estimates were in the range 313-361 bp.

Up to tenfold variation was observed between the total peak areas of the LH-PCR electropherograms, reflecting a corresponding variation in PCR amplicon yield. Both quantity and quality variations of the community DNA template may have caused this variation. However, the LH-PCR profiling proved robust, as replicate runs of the same samples with severalfold variations in total peak area showed no more than two LHFs of deviation in community richness estimates and correspondingly coinciding diversities and community structures (data not shown). In the majority of samples, the $1 \%$ threshold value for fluorescent signal was close to the detection level, as it corresponded to peaks which just slightly exceeded the noise level of the employed detection system. In some control samples (no additions), noise occasionally obscured the detection of the minor peaks due to weak overall signal strength.

All kerosene or fertilizer amended enclosures rapidly developed community profiles which were distinct from the indigenous community, as reflected in the composition of the control units. At day 18, the kerosene only enclosures represented the most extreme deviation, as just two LHF peaks, $\mathrm{LHF}_{340}$ and $\mathrm{LHF}_{345}$, constituted $88 \%$ of the total peak area (Fig. 1). Fragments of length $340 \mathrm{bp}$ were not detected in the control units. The two fertilized experimental groups showed similarity in LHF composition, with strong presences of $\mathrm{LHF}_{316}$ and $\mathrm{LHF}_{342}$ as common features. 


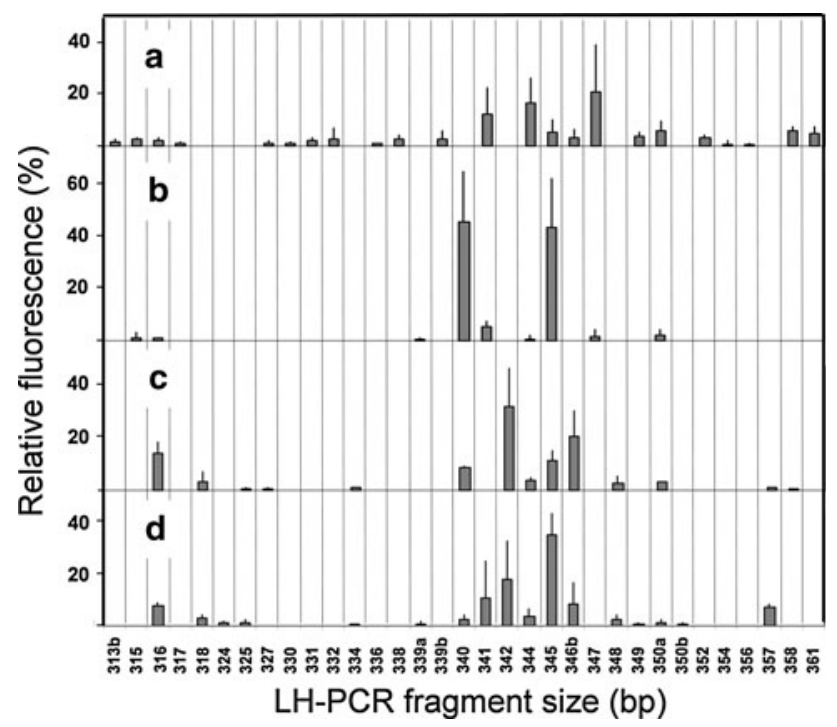

Fig. 1 Distribution of length-heterogeneity fragment sizes in the different treatment groups at day 18 of the experiment. a control enclosures, no additions; b only kerosene added; c only fertilizer added; d kerosene + fertilizer added. Each column represents the mean percentage values of three replicate experimental units \pm SD

The frequency distributions of all LHFs for all treatments and sampling times are presented in Online Resource Fig. S1. The species richness estimates for quantitatively significant community OTUs based on these data are presented (Fig. 2) as numbers of LHFs in each sample. This indicator co-varied closely with the well-established Shannon-Weaver and Simpson diversity indices based on the same fragment data (Fig. S2 of Online Resource). For practical reasons, the control units were only sampled at the start of the experiment, at day 18 and at the day of termination (day 78). The three sampling dates showed highly similar OTU richness, i.e. average values in the range 20-21

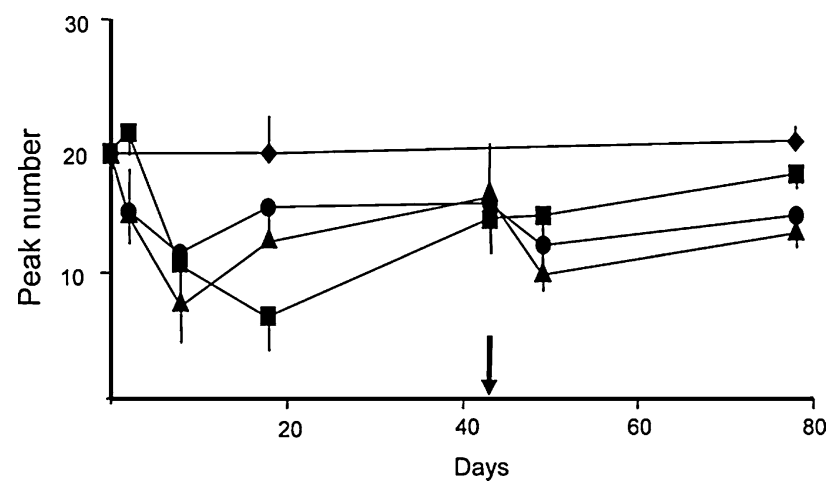

Fig. 2 Community richness development in different treatment groups expressed as the number of fragments in the LH-PCR profiles. Diamonds control units, squares kerosene alone, circles fertilizer alone, triangles kerosene + fertilizer. Data points represent mean values \pm $\mathrm{SD}$ for triplicate enclosures receiving the same treatment. The arrow indicates second addition of fertilizer at day 43
LHFs. As well, the underlying community structure data (Online Resource Fig. S1) confirmed high identity in community composition in the control units. Although temporary, more extreme community divergences in between the infrequent samplings cannot be excluded, and the data more likely confirm a stable community composition throughout the experimental period.

All enclosures added kerosene or fertilizer showed markedly reduced LHF richness figures relative to the control enclosures immediately after the onset of the experiment. Minimum values were reached at day 8 or day 18. The subsequent slow recoveries in LHF numbers were set back by the repeated addition of the fertilizer at day 43 , while the unfertilized kerosene alone units maintained a continuous increase in OTU richness. The statistical significance of the observed changes was confirmed by two-way ANOVA (treatment $\times$ time). The null hypothesis was rejected for both of the variables and their interaction $(P \leq 0.004)$.

\section{Community structure}

Temporal and treatment effects on bacterial community structure were visualized by a multivariate principal components analysis (PCA) of the LHF distribution data. The majority of the 40 LHFs contributed modestly to explained variation, and just the 18 LHFs with loading values $\geq 0.15$ units on PC 1 or PC 2 are identified in Fig. 2a. They gave the main contributions to the 29 and $18 \%$ explained variance, respectively, by PC 1 and PC 2 . The employed log transformation of the relative peak areas did not fully level the contributions to variance by common and rare LHFs (data not shown). Consequently, the loadings of the individual LHFs in part reflect their overall quantitative contribution and in part their contribution to explained differences between treatments and sampling times.

Nine LHFs were positively correlated with the relocation from quadrant I (negative scores along both axes) to quadrants II, III, and IV of the PCA score plot of samples from kerosene and fertilizer amended enclosures (Fig. 2b). The altogether 9 samplings from the control enclosures (3 spatially separated units times 3 points in time) remained rather densely clustered in quadrant I and showed no detectable temporal trend. Hence, at this level of resolution, the unamended beach sediment maintained a stable bacterial community structure throughout the 78 days from early July to late September. The common trend in the immediate community responses induced by the addition of the kerosene or the fertilizer was in the direction of positive scores along PC 1 . This process was largely explained by the rapid and strong emergence of $\mathrm{LHF}_{342}$ and it was somewhat slower and more ambiguous in the kerosene-alone enclosures than in the fertilized units. However, between day 8 and day 18 of the experiment, the kerosene-alone enclosures 
went through a strong shift in community structure and from day 18 , the sample scores stabilized in quadrant IV of the PCA plot. The consistently dense clustering of scores indicated highly similar community structure developments in the three kerosene-alone enclosures, separated by $10 \mathrm{~m}$ along the beach. The most notable feature of these communities was the strong emergence of $\mathrm{LHF}_{340}$ and consistent presence of $\mathrm{LHF}_{341}$ and $\mathrm{LHF}_{347}$ (see also Fig. S1 of Online Resource).

The fertilizer alone and the kerosene + fertilizer communities were distinct from the kerosene-alone communities for the last 60 days of the experiment. On the other hand, no conclusive distinction could be made between the community structures of the two variants of fertilized enclosures, indicating that the fertilizer exerted a strong impact on community structure if kerosene and fertilizer were added together. The stabilized communities of the fertilized enclosures were particularly distinguishable by the presence of LHFs of length 316, 318, 342, and $348 \mathrm{bp}$.

\section{Cultivable hydrocarbon-degrading bacteria}

We investigated to what extent major community inhabitants according to the cultivation-independent approach were also represented among cultivated kerosene growing bacteria in kerosene or fertilizer affected enclosures. A collection of 45 kerosene-consuming isolates were obtained by sampling predominant colony morphotypes from enclosures comprising all four treatments on day 49 of the experiment. The isolates were identified to the rank of family or genus according to their partial 16S rRNA gene sequence (RDP Classifier). The majority, 35 isolates, were affiliated to the Gamma-proteobacteria, 4 to Alpha-proteobacteria, 5 to the Bacteroidetes and 1 to the Actinobacteria (Table 1). The major gamma-proteobacterial groups, i.e. Pseudoalteromonas, Pseudomonadaceae and Shewanella spp., were particularly prevalent in fertilized enclosures, while the remaining phylogenetic groups were more frequently obtained from enclosures added just the kerosene.

The LH-PCR fragment lengths of the isolates were related to the prominent LHFs of the kerosene and fertilizer affected enclosures. Out of the altogether 11 different phylogenetic groups represented among the hydrocarbondegrading isolates (Table 1), 9 showed coinciding fragment lengths with the LHFs of quadrants II, III, and IV of the PCA loadings plot (Fig. 2a). The Pseudoalteromonas, Flavobacterium and Psychrobacter taxa were associable with the positive PC1/negative PC 2 scores typical of the fertilizer-amended enclosures during the initial 1-2 weeks of the experiment.

Nine Pseudomonadacea isolates, including five from kerosene alone enclosures, showed a LH-PCR fragment length of $341 \mathrm{bp}$. This suggested a pseudomonad origin of
Table 1 Phylogenetic group assignment of isolates and clones by the RDP Classifier

\begin{tabular}{|c|c|c|c|c|}
\hline \multirow[t]{2}{*}{$\begin{array}{l}\text { Phylogenetic } \\
\text { group }\end{array}$} & \multirow[t]{2}{*}{$\begin{array}{l}\text { Number of } \\
\text { isolates }\end{array}$} & \multirow[t]{2}{*}{$\begin{array}{l}\text { Sample } \\
\text { source }^{\mathrm{a}}\end{array}$} & \multicolumn{2}{|c|}{$\begin{array}{l}\text { Fragment } \\
\text { length (bp) }\end{array}$} \\
\hline & & & LHF & Sequence \\
\hline \multicolumn{5}{|l|}{ Gamma-proteobacteria } \\
\hline Glaciecola & 3 & $\mathrm{~F}$ & 340 & 340 \\
\hline Halomonadaceae & 1 & $\mathrm{~K}$ & 346 & 346 \\
\hline Pseudoalteromonas & 9 & $\mathrm{~F}, \mathrm{~K} / \mathrm{F}, \mathrm{C}$ & 342 & 342 \\
\hline Pseudomonadaceae & 9 & $\mathrm{~F}, \mathrm{~K}, \mathrm{~K} / \mathrm{F}, \mathrm{C}$ & 341 & 342 \\
\hline Psychrobacter & 3 & $\mathrm{~F}, \mathrm{~K} / \mathrm{F}$ & 344 & 344 \\
\hline Psychromonas & 3 & $\mathrm{~K}, \mathrm{C}$ & 349 & 350 \\
\hline Shewanella & 7 & $\mathrm{~F}, \mathrm{~K}, \mathrm{C}$ & 348 & 348 \\
\hline Moraxellaceae & - & $\mathrm{K}$ & 340 & 340 \\
\hline \multicolumn{5}{|l|}{ Alpha-proteobacteria } \\
\hline Rhodobacteraceae & 4 & $\mathrm{~K}$ & 318 & 318 \\
\hline \multicolumn{5}{|l|}{ Actinobacteria } \\
\hline Microbacteriaceae & 1 & $\mathrm{~K}$ & 345 & 346 \\
\hline \multicolumn{5}{|l|}{ Bacteroidetes } \\
\hline Flavobacterium & 4 & $\mathrm{~K}, \mathrm{~K} / \mathrm{F}, \mathrm{C}$ & 342 & 343 \\
\hline Winogradskyella & 1 & $\mathrm{~K}$ & 348 & 349 \\
\hline
\end{tabular}

The lengths of the 27F/338R amplicons are estimated by LH-PCR fragment analysis and by sequencing of the relevant region of the $16 \mathrm{~S}$ rRNA genes

${ }^{\text {a }} K$ kerosene only, $K / F$ kerosene + fertilizer, $F$ fertilizer only; $C$ control (no additions)

${ }^{\mathrm{b}}$ Cloned 16S rRNA gene sequence

$\mathrm{LHF}_{341}$, which was prevalent in these enclosures. The fragment length of two isolates overlapped with $\mathrm{LHF}_{345}$, pointing to Halomonadaceae and Microbacteriaceae spp. as putative sources of this peak. No isolates from the kerosene-alone enclosures showed matching fragment lengths with the third prominent LHF, at $340 \mathrm{bp}$, despite a heavy presence also on the day of viable bacteria sampling. Consequently, a cloning approach was followed. Seven out of 30 randomly picked transformants generated $340 \mathrm{bp}$ LH-PCR fragments. Their partial 16S rRNA gene sequences showed one to affiliate with Glaciecola sp., while the remaining six sequences were identical, but without counterparts among the isolates. The nearly full-length sequence of one cloned gene and subsequent evolutionary lengthbased phylogenetic inference affiliated these clones with the Alkanindiges/Acinetobacter clade of Moraxellaceae however with no more than $93 \%$ sequence identity with the closest established species, A. illinoisensis (Online resource Fig. S3). Fragment lengths $<320$ bp suggest an alfa-proteobacterial origin (Suzuki et al. 1998) of the source bacteria of $\mathrm{LHF}_{316}$ and $\mathrm{LHF}_{318}$, which were predominantly found in the communities of fertilized enclosures. Four Rhodobacteraceae isolates with identical partial 16S rRNA gene 
Fig. 3 Principal component analysis of the complete LH-PCR data set with the 40 established LH fragments as variables. a Loadings of the fragments on the first two principal components. Just the 18 fragments with PC 1 and/or PC 2 loadings exceeding 0.15 are identified in the graph. Identities of kerosene-consuming isolates are indicated next to the community LH fragments of matching length. b Sample scores on the first two principal components. For clarity, the different treatment groups are presented in separate figures: $b-1$, kerosene alone; $b-2$, fertilizer alone; $b-3$, kerosene + fertilizer. The triangulated data points comprise scores of the three enclosures receiving identical treatment sampled at the same date, and identical point symbols represent the same enclosure at all dates. Days from start of the experiment are given as encircled numbers; the encircled pool of filled symbols gives the scores of the control enclosures

sequences and with LH-PCR fragment lengths of $318 \mathrm{bp}$ were obtained, while no isolates matched the $\mathrm{LHF}_{316}$. Putative Shewanella spp. were isolated repeatedly from the fertilized enclosures and appeared as a main contributor to the $\mathrm{LHF}_{348}$.

The obtained level of LH-PCR resolution made the separation of phylogenetically distinct bacteria with identical 27F/338R sequence lengths possible to some extent. Isolates confidently affiliated to the taxa of Pseudomonadaceae or Pseudoalteromonas, respectively, by the RDP Classifier program all had sequence lengths of $342 \mathrm{bp}$. However, their median 27F/338R LH-PCR product sizes differed, resulting in $1 \mathrm{bp}$ separation by rounding off to nearest integer (Table 1). Other taxon pairs of identical sequence length, such as Halomonadaceae and Microbacteriaceae (both $345 \mathrm{bp}$ ), were inseparable by fragment analysis, while the Pseudoalteromonadaceae/Flavobacterium and Shewanella/ Winogradskyella pairs showed overlapping LH-PCR values despite 1 bp separation in sequence lengths (Fig. 3).

\section{Discussion}

We employed a 16S rRNA gene-based community fingerprint approach (LH-PCR) to elucidate the dynamics of bacterial community change in a hydrocarbon-affected Arctic intertidal beach sediment. Although the resolving power of the most directly comparable method, terminal restriction fragment length polymorphism (T-RFLP), is principally higher by employing a wider range of possible fragment lengths, the LH-PCR appears as a simple approach to obtain community fingerprints with a reasonable level of resolution. When employed on a hydrocarbon contaminated environment, the method has been shown to perform at least as well as T-RFLP with respect to reproducibility and reflection of diversity and community differences (Mills et al. 2003). In our study, the LH-PCR community profiling proved efficient to elucidate the questions raised on the individual effects of the hydrocarbon contaminant and the fertilizer on bacterial community development. Both
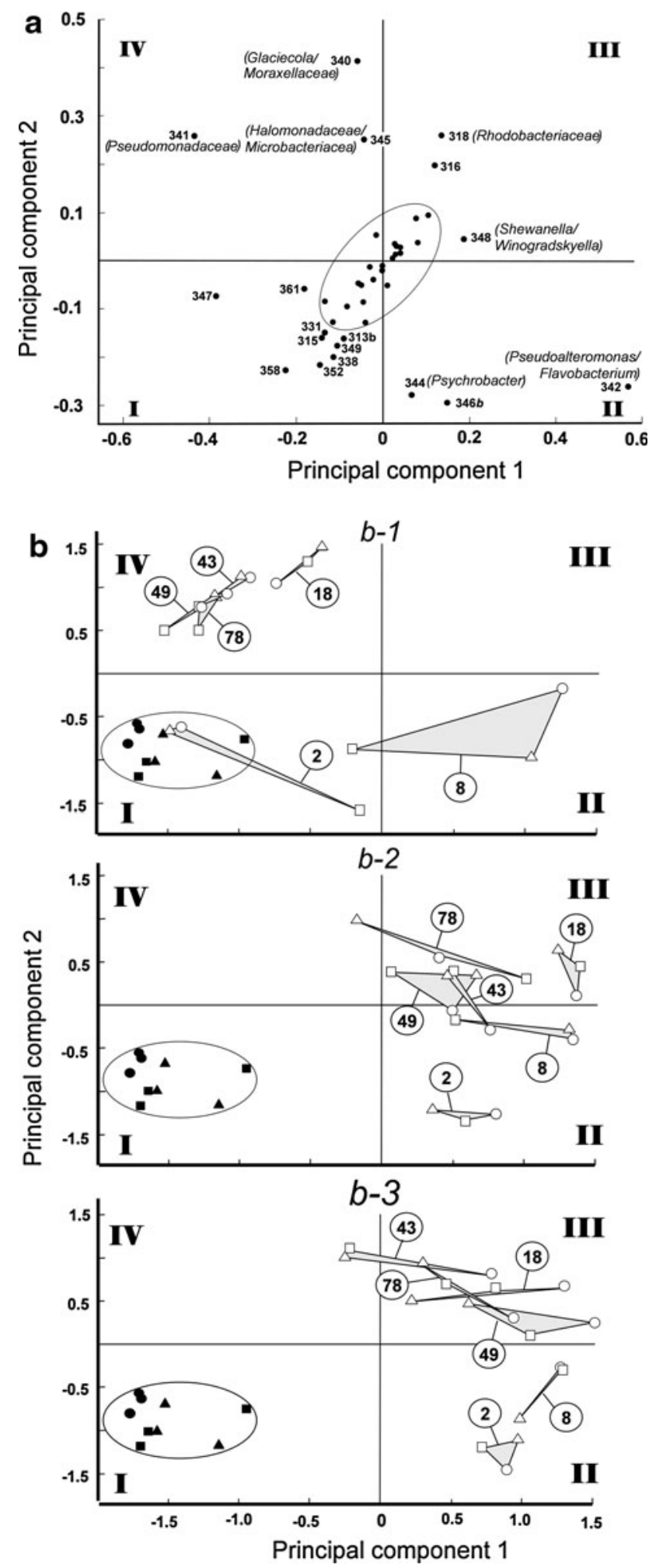

temporal and treatment effects were evident on the background of random variations between spatially separated experimental units receiving identical treatments.

The expected effect of introducing abundant quantities of allochtonous biodegradable organic matter into a bacterial 
community is dominance by opportunistic bacteria able to thrive on these energy and carbon sources. In accordance with this, we observed rapid increases in viable bacterial counts (Røberg et al. 2007) and declines in bacterial community richness (this study) in the present experimental system after addition of kerosene, oleophilic fertilizer or both. However, distinct differences in community structure developments were observed between experimental units receiving the kerosene-type hydrocarbon contaminant alone and the ones receiving the oleophilic fertilizer, either alone or concomitantly with the kerosene. This difference was evidenced both as faster and more uniform community responses during the first week in the fertilized units and as a lasting separation by community structure throughout the remaining part of the experimental period. In the kerosenealone enclosures, the initial large spread of the PCA scores between replicate units was followed by an equally noticeable dense and stable clustering of the scores in quadrant III of the PCA plot throughout the remaining part of the experiment. This dynamic indicated that (1) the initial response time of the indigenous bacterial community to the kerosene addition was sensitive to some minor variation in physicochemical conditions between the replicate enclosures, (2) the degree of development of a transient community structure, characterized by positive PC 1 /negative PC 2 , was more unpredictable in kerosene alone than in the fertilized enclosures, and (3) the small, but stable kerosene residual in the upper sediment layer (Røberg et al. 2007) exerted a marked selective force which promoted a high degree of both spatial and temporal stability in this treatment group throughout most of the experimental period.

The two treatment groups with fertilizer were not confidently separable, neither by their immediate response to the additions nor by their stabilized community profiles later in the experimental period. Assignment of LH-PCR fragment lengths to isolates of hydrocarbon-degrading bacteria furthermore suggested the same phylogenetic groups of hydrocarbon degraders to form major constituents of the two categories of fertilized enclosures. Hence, the fertilizer shaped the community structure to a larger extent than the hydrocarbon contaminant when the two were added concomitantly. These results substantiated the previous observation from the same experimental system of highly similar developments in the viable counts of hydrocarbon-degrading bacteria in experimental units receiving kerosene + fertilizer or fertilizer alone (Røberg et al. 2007).

In the case of inorganic fertilizers, their evident bioremediation and bacterial community structure effects are to raise the levels of growth-limiting nitrogen and phosphate nutrients and thereby boost the growth and catabolic rate of hydrocarbon-degrading bacteria. The effects of adding an oleophilic fertilizer, like the Inipol ${ }^{+}$employed in the present experiment, are more complex. Besides promoting growth of hydrocarbon-degrading bacteria by providing nitrogen, phosphorous and surfactant action, most ingredients in the fertilizer are easily biodegradable carbon and energy sources in their own right and should thereby promote rapid growth of a wider range of bacteria. According to the manufacturer, the Inipol $^{+}$fertilizer contains no hydrocarbon ingredients (Périé; personal communication) and consequently, the observed priming effect on kerosenegrowing bacteria in the absence of the kerosene has no selfevident nutritional source. However, the Inipol ${ }^{+}$contains close to $25 \%$ long-chain free fatty acids, predominantly oleic acid, as a microemulsion stabilizer and a booster of bacterial growth (Ladousse and Tramier 1991). The growth of alkane degraders on the fertilizer is most likely attributable to this component. Fatty acids are key intermediates in the aerobic degradation pathway of alkanes, and our study indicates that the bacterial phylotypes which responded readily to the fatty acid addition also carried the genotype for expressing alkane hydroxylation. Furthermore, the fact that the hydrocarbon degraders isolated from fertilizer alone enclosures were enriched by cultivation on a pure kerosene-minerals medium suggests that these phylotypes have the potential for degrading alkane contaminants also in nature. On the other hand, the putative fatty acid induced boost of alkane-degrading bacteria do not necessarily lead to immediate hydrocarbon biodegradation, as previous studies have shown preference for the fatty acids to the more recalcitrant alkanes in mixed systems-resulting in a delayed onset of hydrocarbon biodegradation (Rivet et al. 1993; Swannell et al. 1996).

Two preceding field trials, both at British locations, have presented conflicting conclusions regarding the capacity of oil contaminations to inflict bacterial community changes in intertidal beach sediment if not amended with fertilizer. In accordance with our study, Swannell et al. (2000) report marked community structure changes in experimental plots added oil without fertilizer. On the other hand, Röling et al. (2004) observed no significant differences in DGGE band patterns between untreated controls and experimental plots receiving oil alone. In our experiment, the community changes were swift even at the low prevailing summer temperatures of the High Arctic, as the richness and diversity indices approached minimum values within the first week. The added kerosene may have influenced the bacterial community both by promoting proliferation of phylotypes which thrived on this carbon and energy source and by inhibiting the growth of groups sensitive to elevated hydrocarbon concentrations. Both effects may have been at work in the kerosene alone enclosures as the distinct effects on bacterial community composition were accompanied by noticeably modest effects on both total and viable bacterial counts of adding just the kerosene (Røberg et al. 2007). 
The rather low LH-PCR-based community complexities in the kerosene and fertilizer affected experimental units gave grounds for provisional phylotype identification of important hydrocarbon-degrading community inhabitants through coincidence in fragment sizes of isolates and community LHFs. Similar approaches have previously been used to explore other kinds of microbial systems (Lazzi et al. 2004; Connon et al. 2005; Kolehmainen et al. 2008). Seven out of the nine LHFs which were the principal distinguishers between the kerosene- and fertilizer-affected enclosures on the one side and the control units (PC 1 and PC 2 negative) on the other had fragment lengths which corresponded with isolated hydrocarbon degraders. However, the employed phylotype inference is merely indicative. Firstly, important groups may have been unrepresented due to the well-known lack of cultivability of many prokaryotic lineages in natural environments (Amann et al. 1995). Secondly, the collection of isolates may have been biased with respect to the true composition of cultivable phylogenetic groups in these communities. Besides the inherent stochastic nature of the collection of isolates, the sampling was, for practical reasons, limited to a single date 7 weeks into the experimental period. Finally, there is an ambiguity created by multiple phylotypes matching the same LH-PCR fragment lengths (Suzuki et al. 1998). In the present study, several cases of at least two phylogenetically distinct hydrocarbon-degrading isolates within a single LHF were observed. Despite these limitations, the case is strong for the repeatedly isolated hydrocarbon-degrading bacterial taxa as prominent members of the kerosene- and fertilizer-affected enclosures. Several studies related to crude oil contamination of sea water, sea ice or beach sediment in the polar regions point to the same taxa, i.e. Flavobacterium, Halomonas, Glaciecola, Pseudoalteromonas, Pseudomonas, Psychrobacter, Rhodococcus, Shewanella, as significant hydrocarbon degraders in such environments (Grossman et al. 2000; Yakimov et al. 2004; Deppe et al. 2005; Gerdes et al. 2005; Brakstad et al. 2008).

The cloning approach pointed out an operational taxonomic unit within the Alkanindiges/Acinetobacter clade of Moraxellaceae with no closely related cultivated relatives as a predominant element of the $\mathrm{LHF}_{340}$ in the kerosene alone enclosures. This population may have contributed to the apparent lack of accordance between the modest effect on viable counts (Røberg et al. 2007) and profound effect on community structure (this study) of adding just kerosene to the experimental enclosures. Both Alkanindiges and Acinetobacter spp. have previously been shown to be prevalent in hydrocarbon-contaminated environments (Venkateswaran et al. 1991; Kämpfer et al. 1993; Bogan et al. 2003) and additional hydrocarbon-degrading phylotypes within the same sub-branch of the Moraxellaceae seem plausible.
The identities of the $\mathrm{LHF}_{316}$ and $\mathrm{LHF}_{346 \mathrm{~b}}$, both characteristic of the experimental enclosures, remained elusive both by the cultivation and cloning approaches. A possible candidate for $\mathrm{LHF}_{346 \mathrm{~b}}$ is Alcanivorax spp. Representatives of this rather recently described group of bacteria have been shown to propagate rapidly and become prominent in early phases in several marine alkane-contaminated environments (Head et al. 2006; Cappello et al. 2007). Alcanivorax spp. have compatible 27F/338R LHFs, as both 346 and $347 \mathrm{bp}$ are reported for different strains deposited in the GenBank database.

In conclusion, our study indicated the oleophilic fertilizer to be highly influential on both the immediate response and the more long-term community structure when added as an amendment to a kerosene-type hydrocarbon contamination. The dual use of the LH-PCR technique on environmental samples and hydrocarbon-degrading isolates suggested most prominent OTUs in the kerosene- or fertilizer-affected bacterial communities to be represented by cultivable hydrocarbon-degrading bacteria from the same type of experimental units. However, a few OTUs, including a hitherto unspeciated phylotype within the Moraxellaceae group, appeared as significant populations in the hydrocarbon-contaminated enclosures, but remained recalcitrant to cultivation on hydrocarbonaceous media.

Acknowledgments This work was financed by grants from Total E\&P Norway AS and the Norwegian College of Fishery Science at the University of Troms $\varnothing$. The study was also supported financially by the Roald Amundsen Centre for Arctic Research and the Helge and Kellfrid Jacobsen Foundation of the University of Troms $\varnothing$. Laboratory facilities during fieldwork were provided by the University Centre in Svalbard. The Inipol bioremediation products were kindly provided by CECA SA, France. We thank Raul Primicerio for advice on the principal component analysis.

Open Access This article is distributed under the terms of the Creative Commons Attribution Noncommercial License which permits any noncommercial use, distribution, and reproduction in any medium, provided the original author(s) and source are credited.

\section{References}

Amann RI, Ludwig W, Schleifer KH (1995) Phylogenetic identification and in situ detection of individual microbial cells without cultivation. Microbiol Rev 59:143-169

Ashelford KE, Chuzhanova NA, Fry JC, Jones AJ, Weightman AJ (2005) At least 1 in 20 16S rRNA sequence records currently held in public repositories is estimated to contain substantial anomalies. Appl Environ Microbiol 71:7724-7736

Atlas RM (1995) Petroleum biodegradation and oil spill bioremediation. Marine Pollut Bull 31:178-182

Ausubel FM, Brent R, Kingston RE, Moore DD, Seidman JG, Smith JA, Struhl K (1994) Current protocols in molecular biology, vol 1. Wiley, New York

Bogan BW, Sullivan WR, Kayser KJ, Derr KD, Aldrich HC, Peterek JR (2003) Alkanindiges illinoisensis gen. nov., sp nov., an obligately hydrocarbonoclastic, aerobic squalane-degrading 
bacterium isolated from oilfield soils. Int J Syst Evol Microbiol 53:1389-1395

Brakstad OG, Nonstad I, Faksness LG, Brandvik PJ (2008) Responses of microbial communities in Arctic sea ice after contamination by crude petroleum oil. Microb Ecol 55:540-552

Cappello S, Denaro R, Genovese M, Giuliano L, Yakimov MM (2007) Predominant growth of Alcanivorax during experiments on "oil spill bioremediation" in mesocosms. Microbiol Res 162:185-190

Cole JR, Chai B, Farris RJ, Wang Q, Kulam-Syed-Mohideen AS, McGarrell DM, Bandela AM, Cardenas E, Garrity GM, Tiedje JM (2007) The ribosomal database project (RDP-II): introducing myRDP space and quality controlled public data. Nucleic Acids Res 35:D169-D172

Connon SA, Tovanabootr A, Dolan M, Vergin K, Giovannoni SJ, Semprini L (2005) Bacterial community composition determined by culture-independent and -dependent methods during propanestimulated bioremediation in trichloroethene-contaminated groundwater. Environ Microbiol 7:165-178

Dandie CE, Thomas SM, McClure NC (2001) Comparison of a range of green fluorescent protein-tagging vectors for monitoring a microbial inoculant in soil. Lett Appl Microbiol 32:26-30

Delille D, Coulon F (2008) Comparative mesocosm study of biostimulation efficiency in two different oil-amended Antarctic soils. Microb Ecol 56:243-252

Delille D, Bassères A, Dessommes A (1998) Effectiveness of bioremediation for oil-polluted Antarctic seawater. Polar Biol 19:237-241

Delille D, Pelletier E, Rodriguez-Blanco A, Ghiglione JF (2009) Effects of nutrient and temperature on degradation of petroleum hydrocarbons in sub-Antarctic coastal seawater. Polar Biol 32:1521-1528

Deppe U, Richnow HH, Michaelis W, Antranikian G (2005) Degradation of crude oil by an Arctic microbial consortium. Extremophiles 9:461-470

Fingas MF (2004) Modeling evaporation using models that are not boundary-layer regulated. J Hazard Mater 107:27-36

Gerdes B, Brinkmeyer R, Dieckmann G, Helmke E (2005) Influence of crude oil on changes of bacterial communities in Arctic sea-ice. FEMS Microbiol Ecol 53:129-139

Grossman M, Prince R, Garret R, Bare R, Lee K, Sergy G, Owens E, Guenette C (2000) Microbial diversity in oiled and unoiled shoreline sediments in the Norwegian Arctic. In: Bell CR, Brylinsky M, Johnson-Green P (eds) Proceedings of the 8th international symposium on microbial ecology. Atlantic Canada Society for Microbial Ecology, Halifax, Canada

Head IM, Jones DM, Röling WFM (2006) Marine microorganisms make a meal of oil. Nature Rev Microbiol 4:173-182

Jarsjö J, Destouni G, Yaron B (1997) On the relation between viscosity and hydraulic conductivity for volatile organic liquid mixtures in soils. J Contam Hydrol 25:113-127

Jiménez N, Viñas M, Bayona JM, Albaiges J, Solanas AM (2007) The Prestige oil spill: bacterial community dynamics during a field biostimulation assay. Appl Microbiol Biotechnol 77:935-945

Kämpfer P, Steiof M, Becker PM, Dott W (1993) Characterization of chemoheterotrophic bacteria associated with the in situ bioremediation of a waste-oil contaminated site. Microb Ecol 26:161-188

Kolehmainen RE, Tiirola M, Puhakka JA (2008) Spatial and temporal changes in Actinobacterial dominance in experimental artificial groundwater recharge. Water Res 42:4525-4537

Ladousse A, Tramier B (1991) Results of 12 years of research in spilled oil bioremediation: Inipol EAP 22. Proceedings 12th International Oil Spill Conference. American Petroleum Institute, Washington

Lazzi C, Rossetti L, Zago M, Neviani E, Giraffa G (2004) Evaluation of bacterial communities belonging to natural whey starters for Grana Padano cheese by length heterogeneity-PCR. J Appl Microbiol 96:481-490
Macnaughton SJ, Stephen JR, Venosa AD, Davis GA, Chang YJ, White DC (1999) Microbial population changes during bioremediation of an experimental oil spill. Appl Environ Microbiol 65:3566-3574

Margesin R, Schinner F (1999) Biological decontamination of oil spills in cold environments. J Chem Technol Biotechnol 74:381-389

Margesin R, Hammerle M, Tscherko D (2007) Microbial activity and community composition during bioremediation of diesel-oil-contaminated soil: Effects of hydrocarbon concentration, fertilizers, and incubation time. Microb Ecol 53:259-269

Mearns AJ (1997) Cleaning oiled shores: putting bioremediation to the test. Spill Sci Technol Bull 4:209-217

Mills DK, Fitzgerald K, Litchfield CD, Gillevet PM (2003) A comparison of DNA profiling techniques for monitoring nutrient impact on microbial community composition during bioremediation of petroleum-contaminated soils. J Microbiol Methods 54:57-74

Muyzer G, Dewaal EC, Uitterlinden AG (1993) Profiling of complex microbial populations by denaturing gradient gel electrophoresis analysis of polymerase chain reaction-amplified genes coding for 16S rRNA. Appl Environ Microbiol 59:695-700

Pitcher DG, Saunders NA, Owen RJ (1989) Rapid extraction of bacterial genomic DNA with guanidium thiocyanate. Lett Appl Microbiol 8:151-156

Prince RC (2005) The microbiology of marine oil spill bioremediation. In: Ollivier B, Magot M (eds) Petroleum microbiology. ASM Press, Washington

Rivet L, Mille G, Bassères A, Ladousse A, Gerin C, Acquaviva C, Bertrand JC (1993) N-alkane biodegradation by a marine bacterium in the presence of an oleophilic nutriment. Biotechnol Lett 15:637-640

Røberg S, Stormo SK, Landfald B (2007) Persistence and biodegradation of kerosene in high-Arctic intertidal sediment. Marine Environ Res 64:417-428

Röling WFM, Milner MG, Jones DM, Lee K, Daniel F, Swannell RJP, Head IM (2002) Robust hydrocarbon degradation and dynamics of bacterial communities during nutrient-enhanced oil spill bioremediation. Appl Environ Microbiol 68:5537-5548

Röling WFM, Milner MG, Jones DM, Fratepietro F, Swannell RPJ, Daniel F, Head IM (2004) Bacterial community dynamics and hydrocarbon degradation during a field-scale evaluation of bioremediation on a mudflat beach contaminated with buried oil. Appl Environ Microbiol 70:2603-2613

Shannon CE, Weaver W (1963) The mathematical theory of communication. University of Illinois Press, Urbana, p 125

Simpson EH (1949) Measurement of diversity. Nature 163:688

Suzuki M, Rappé MS, Giovannoni SJ (1998) Kinetic bias in estimates of coastal picoplankton community structure obtained by measurements of small-subunit rRNA gene PCR amplicon length heterogeneity. Appl Environ Microbiol 64:4522-4529

Swannell RPJ, Lee K, McDonagh M (1996) Field evaluations of marine oil spill bioremediation. Microbiol Rev 60:342-365

Swannell RPJ, Mitchell DJ, Waterhouse JC, Miskin IC, Head IM, Petch S, Jones DM, Willis A, Lee K, Lepo JE (2000) Impact of bioremediation treatments on the biodegradation of buried oil and predominant bacterial populations. In: Bell CR, Brylinsky M, Johnson-Green P (eds) Proceedings 8th international symposium on microbial ecology. Atlantic Canada Society for Microbial Ecology, Halifax

Thompson JD, Gibson TJ, Plewniak F, Jeanmougin F, Higgins DG (1997) The CLUSTAL_X windows interface: flexible strategies for multiple sequence alignment aided by quality analysis tools. Nucleic Acids Res 25:4876-4882

Vázquez S, Nogales B, Ruberto L, Hernández E, Christie-Oleza J, Lo Balbo A, Bosch R, Lalucat J, Mac Cormack W (2009) Bacterial community dynamics during bioremediation of diesel oil-contaminated Antarctic soil. Microb Ecol 57:598-610 
Venkateswaran K, Iwabuchi T, Matsui Y, Toki H, Hamada E, Tanaka H (1991) Distribution and biodegradation potential of oil-degrading bacteria in north eastern Japanese coastal waters. FEMS Microbiol Ecol 86:113-121

Wang Q, Garrity GM, Tiedje JM, Cole JR (2007) Naïve Bayesian classifier for rapid assignment of rRNA sequences into the new bacterial taxonomy. Appl Environ Microbiol 73:5261-5267

Wold S, Esbensen K, Geladi P (1987) Principal component analysis. Chemometr Intell Lab Syst 2:37-52

Xu R, Obbard JP (2003) Effect of nutrient amendments on indigenous hydrocarbon biodegradation in oil-contaminated beach sediments. J Environ Qual 32:1234-1243
Yakimov MM, Gentile G, Bruni V, Cappello S, D'Auria G, Golyshin PN, Giuliano L (2004) Crude oil-induced structural shift of coastal bacterial communities of rod bay (Terra Nova Bay, Ross Sea, Antarctica) and characterization of cultured cold-adapted hydrocarbonoclastic bacteria. FEMS Microbiol Ecol 49:419-432

Zhu X, Venosa AD, Suidan MT (2004) Literature review on the use of commercial bioremediation agents for cleanup of oil-contaminated estuarine environments. US Environmental Protection Agency. National Risk Management Research Laboratory, Cincinnati 